\title{
Plasma lipids and coagulation in patients with arteriosclerotic dementia
}

\author{
V. M. ANDREOLI, S. FERRARI, C. R. SIRTORI, \\ G. BIASI, AND M. MORANDINI \\ From the Neuropsychiatric Hospital, Verona-Ponton, and Enrica Grossi Paoletti Centre \\ for Metabolic Diseases, University of Milan, 20129 Milan, Italy
}

SYNOPSIS Plasma lipids and lipoproteins, glucose, uric acid, and haemocoagulative parameters were studied in a group of 22 elderly hospitalized patients with arteriosclerotic dementia, and compared with those of a control group of a similar age. No significant differences were found in lipids, lipoproteins, glucose, or uric acid but the fibrinogen level was significantly raised in the group with arteriosclerotic dementia. A comparison of the metabolic parameters of the dementia patients with those of a group of subjects with peripheral occlusive arteriosclerosis showed, on the other hand, that this latter group had significantly raised plasma triglycerides as well as a significantly higher incidence of the Fredrickson phenotypes of hyperlipoproteinaemia. These findings indicate that the common laboratory parameters used to evaluate arteriosclerosis are not adequate to point out any pathogenic mechanism for arteriosclerotic dementia, and research should therefore be focused in other directions.

Cerebral arteriosclerosis may produce dementia characterized by the loss of higher intellectual capacities, loss of memory and initiative, irritability, and, often, behavioural modifications, such as depression, confusion, and agitation (Mayer et al., 1959). Studies on the biochemical and haemocoagulative parameters of patients with cerebral arteriosclerosis have yielded conflicting results, and no clear-cut pattern has been determined. Mayer et al. (1959) denied that hypercholesteraemia is more frequent in patients with cerebral arteriosclerosis, whereas Heyman et al. (1961) found a very high percentage of hypercholesteraemia among their patients. In a recent study by Acheson and Hutchinson (1972), in patients with cerebral arteriosclerosis showing plasma cholesterol levels above $250 \mathrm{mg}$ per 100 $\mathrm{ml}$, clofibrate treatment lowered serum cholesterol but failed to modify prognosis. According to Pendefunda et al. (1966) in $70 \%$ of patients with cerebral arteriosclerosis increased triglyceride levels could be ascertained, other lipid parameters being normal. Drobinski and Palamarchuk (1969), in a group of 361 young patients (aged 33-35 years) with neurological symptoms of cerebral arteriosclerosis, found increased plasma cholesterol levels and decreased lecithins in $38 \%$ of the cases; arterial pressure was generally normal.

Brancale (1970) found a high frequency of hypercoagulability in 120 patients with cerebral arteriosclerosis, apparently dependent also upon the subject's age, the severity of the process, and concomitant diabetes. Ethnic differences between arteriosclerosis of the circle of Willis in the United States and Japan, indicating that the Japanese have strikingly more severe lesions (Resch et al., 1969), have not been adequately explained. In patients with arteriosclerotic dementia no conclusive data are reported concerning biochemical parameters.

Patients with peripheral occlusive arteriosclerosis tend to have higher blood triglyceride levels than controls, according to Greenhalgh et al. (1971), whereas, according to Cotton et al. (1972) these patients have a practically normal plasma lipid pattern, but exhibit marked alterations in several haemocoagulative tests.

It was our purpose to perform biochemical and haemocoagulative tests in elderly patients 
with arteriosclerotic dementia, admitted to a neuropsychiatric hospital. Dementia generally develops in very severe forms of cerebral arteriosclerosis and it represents one of the more advanced stages of the arteriosclerotic process. The clinical diagnosis was supported by signs of neurological deficit, by mental tests and psychiatric rating scales. These patients were compared with a group of subjects of the same age, without symptoms of cerebral arteriosclerosis. Part of the biochemical investigations were also carried out in a sample of patients with peripheral occlusive arteriosclerosis, and these data were compared with those of the patients with arteriosclerotic dementia.

\section{METHODS}

SUBJECTS Twenty-two hospitalized patients with arteriosclerotic dementia, 33 control subjects with diagnoses other than arteriosclerotic dementia, and 21 patients with peripheral occlusive arteriosclerosis were considered from the Neuropsychiatric Hospital, Verona-Ponton, and the Second Surgical Clinic, University of Milan. Details of age and sex are given in Table 1. All patients were kept on a standard hospital diet, the number of calories being between

TABLE 1

AGE AND SEX DISTRIBUTION IN THREE GROUPS OF SUBJECTS CONSIDERED

\begin{tabular}{lccc}
\hline Groups & Male & Female & $\begin{array}{c}\text { Age } \\
(y r)\end{array}$ \\
\hline Arterioselerotic dementia & 12 & 10 & $70 \cdot 77 \pm 5 \cdot 71$ \\
Controls & 19 & 14 & $66 \cdot 39 \pm 6 \cdot 24$ \\
Peripheral occlusive arteriosclerosis & 21 & - & $62 \cdot 14 \pm 3 \cdot 10$ \\
\hline
\end{tabular}

Means $\pm S D$

1,500 and 2,000 per day. The diagnosis of arteriosclerotic dementia was based upon clinical observation of the patients, the results of an intelligence test (Wechsler-Bellevue II), and a psychiatric rating scale (J. R. Wittenborn). Patients with psychiatric symptoms of dementia were included in the study only if the standard neurological examination showed signs of focal deficit. Eye ground observations were performed by two independent examiners.

Blood pressure measurements were carried out on a 24 hour basis with determinations every two hours.

In patients with peripheral occlusive arterio- 0 sclerosis, digital plethysmography and oscillography were performed, as well as aortography by the Dos Santos technique, unless other clinical findings suggested it was better not to carry out this procedure..? All patients were free from symptoms of liver and $\vec{\Rightarrow}$ kidney damage.

BIOCHEMICAL AND HAEMOCOAGULATION PROCEDURES $\frac{\bar{\sigma}}{\bar{c}}$ Lipids Plasma cholesterol and triglycerides were $\overrightarrow{\widetilde{\sigma}}$ measured after 12 hour fasting by a simultaneous automated procedure (Block et al., 1965; Kesslerळ and Lederer, 1965), and individual phospholipid $\vec{\circ}$ classes were separated according to the method described by Rouser et al. (1966). Lipoprotein $\vec{\omega}$ electrophoresis was performed on agarose gel by the? method of Noble (1968); nephelometry according to Stone et al. (1970); lipoprotein separation by ultra- $\dot{\omega}$ centrifuge was carried out according to the $\mathrm{NIH}_{i 0}^{-}$ procedure (Fredrickson et al., 1968).

Glucose and uric acid Glucose and uric acid wepe을 analysed by automated chemical procedures (Bittnôेand Manning, 1963; Musser and Ortigoza, 1966). $\frac{2}{0} \mathbb{8}$

Coagulative parameters Fibrinogen was determined according to Fearnley and Chakrabarri (196\%;웅 partial thromboplastin time (PTT) according Langdell et al. (1953); prothrombin time (PT) by $\overrightarrow{0}$ Dade Thrombosplastin reagent; platelet count was + on a model F Coulter counter. Euglobulin lysis timeo (ELT) was measured according to Buckell (1958). Statistical differences between results were measured by the two-tailed $t$ test.

\section{RESULTS}

CLINICAL FINDINGS Intelligence tests were applicable to only five subjects with arteriosclerotic dementia, and, according to the Wechsler Bellevue scoring system, their IQs ranged between 57 음 and 72 . In the others the dementia did not allow: verbal communication. The control subjects had? IQs between 69 and 82, and no IQ was recorded for the patients with peripheral occlusive arteriosclerosis who, however, all seemed to have nor-음 mal intellectual functions. Neurological deficits $\frac{7}{2}$ of varying degrees (from mild to severe) and signs of focal deficits were present in all subjects $N$ with arteriosclerotic dementia but in none of then controls or patients with peripheral occlusiven arteriosclerosis. Hypertension (diastolic bloodo 
TABLE 2

LIPIDS, LIPOPROTEINS, GLUCOSE, AND URIC ACID PLASMA LEVELS IN PATIENTS WITH ARTERIOSCLEROTIC DEMENTIA AND CONTROLS (MG/100 ML)

\begin{tabular}{|c|c|c|c|c|c|c|c|}
\hline & Cholesterol & Triglycerides & sf $0 \cdot 20$ & sf $20-400$ & sf 400 & Glucose & Uric acid \\
\hline $\begin{array}{l}\text { Arteriosclerotic } \\
\text { dementia } \\
\text { Controls }\end{array}$ & $\begin{array}{l}207 \cdot 50 \pm 11 \cdot 36 \\
226 \cdot 09 \pm 11 \cdot 38\end{array}$ & $\begin{array}{l}134 \cdot 31 \pm 21 \cdot 96 \\
124 \cdot 39 \pm 7 \cdot 19\end{array}$ & $\begin{array}{l}383 \cdot 27 \pm 20 \cdot 12 \\
406 \cdot 76 \pm 9 \cdot 94\end{array}$ & $\begin{array}{l}175 \cdot 32 \pm 25 \cdot 45 \\
143 \cdot 03 \pm 7 \cdot 20\end{array}$ & $\begin{array}{l}7 \cdot 26 \pm 1 \cdot 00 \\
5 \cdot 93 \pm 0 \cdot 54\end{array}$ & $\begin{array}{r}101 \cdot 68 \pm 6 \cdot 76 \\
93 \cdot 04 \pm 2 \cdot 11\end{array}$ & $\begin{array}{l}4 \cdot 75 \pm 0.31 \\
5 \cdot 14 \pm 0 \cdot 25\end{array}$ \\
\hline
\end{tabular}

Means \pm SEM

No significant differences.

TABLE 3

COAGULATION PARAMETERS IN PATIENTS WITH ARTERIOSCLEROTIC DEMENTIA AND CONTROLS

\begin{tabular}{|c|c|c|c|c|c|}
\hline & $\begin{array}{c}\text { Platelets } \\
\left(\text { per } \mathrm{mm}^{3}\right)\end{array}$ & $\begin{array}{c}P T T \\
(s)\end{array}$ & $\begin{array}{l}P T \\
(\%)\end{array}$ & $\begin{array}{c}\text { Fibrinogen } \\
(\mathrm{mg} / 100 \mathrm{ml})\end{array}$ & $\begin{array}{c}E L T \\
(\min )\end{array}$ \\
\hline $\begin{array}{l}\text { Arteriosclerotic dementia } \\
\text { Controls }\end{array}$ & $\begin{array}{l}194,630 \pm 14,820 \\
184,277 \pm 16,060\end{array}$ & $\begin{array}{l}29 \cdot 15 \pm 0 \cdot 78 \\
31 \cdot 53 \pm 1 \cdot 00\end{array}$ & $\begin{array}{l}91 \cdot 88 \pm 2 \cdot 57 \\
92 \cdot 86 \pm 2 \cdot 05\end{array}$ & $\begin{array}{l}499 \cdot 90 \pm 23 \cdot 35^{*} \\
425 \cdot 71 \pm 17 \cdot 60\end{array}$ & $\begin{array}{l}210 \cdot 90 \pm 11 \cdot 34 \\
199 \cdot 00 \pm 12 \cdot 85\end{array}$ \\
\hline
\end{tabular}

Means \pm SEM

* Significantly different from controls: $\mathrm{P}<0.01$.

TABLE 4

PHOSPHOLIPID LEVELS AND PERCENTAGE OF PHOSPHOLIPID CLASSES IN PATIENTS WITH ARTERIOSCLEROTIC DEMENTIA AND CONTROLS

\begin{tabular}{|c|c|c|c|c|c|}
\hline & $\underset{(m g / 100 \mathrm{ml})}{\text { Total }}$ & $\begin{array}{l}P l+\text { Lys. } \\
\quad(\%)\end{array}$ & $\begin{array}{l}\text { Sph. } \\
(\%)\end{array}$ & $\begin{array}{r}L e \\
(\%)\end{array}$ & $\begin{array}{r}P l \\
(\%)\end{array}$ \\
\hline $\begin{array}{l}\text { Arteriosclerotic dementia } \\
\text { Controls }\end{array}$ & $\begin{array}{c}204 \cdot 60 \pm 0 \cdot 154 \\
234 \cdot 50 \pm 0 \cdot 100 \\
\text { NS }\end{array}$ & $\begin{array}{l}6 \cdot 82 \pm 0 \cdot 47^{*} \\
5 \cdot 47 \pm 0 \cdot 36\end{array}$ & $\begin{array}{l}23 \cdot 39 \pm 0.69 \dagger \\
21 \cdot 04 \pm 0.43\end{array}$ & $\begin{array}{c}67 \cdot 14 \pm 0 \cdot 73 \\
67 \cdot 51 \pm 076 \\
\text { NS }\end{array}$ & $\begin{array}{c}2 \cdot 51 \pm 0 \cdot 16 \\
2 \cdot 66 \pm 0 \cdot 30 \\
\text { NS }\end{array}$ \\
\hline
\end{tabular}

Means + SEM

* Difference from controls: $0.05<\mathrm{P}<0 \cdot 1$.

$\dagger$ Significantly different from controls: $P<0.05$.

TABLE 5

LIPID, GLUCOSE AND URIC ACID PLASMA LEVELS IN PATIENTS WITH ARTERIOSCLEROTIC DEMENTIA AND PERIPHERAL OCCLUSIVE ARTERIOSCLEROSIS (MG/100 ML)

\begin{tabular}{lcccc}
\hline & Cholesterol & Triglycerides & Glucose & Uric acid \\
\hline Arteriosclerotic dementia & $207 \cdot 50 \pm 11 \cdot 36$ & $134 \cdot 31 \pm 21 \cdot 96$ & $101 \cdot 68 \pm 6 \cdot 76$ & $4 \cdot 75 \pm 0 \cdot 31$ \\
Peripheral occlusive arteriosclerosis & $218 \cdot 52 \pm 10 \cdot 65$ & $192 \cdot 66 \pm 24 \cdot 55^{*}$ & $104 \cdot 77 \pm 9 \cdot 41$ & $5 \cdot 42 \pm 0 \cdot 32$ \\
\hline
\end{tabular}

Means \pm SEM.

* Significantly different from patients with AD: $\mathbf{P}<0.01$ 
pressure over $100 \mathrm{mmHg}$ steadily in 12 measurements over 12 hours, together with retinal changes) was present in two patients with arteriosclerotic dementia, and six with peripheral occlusive arteriosclerosis $(P<0.05)$, and in none of the controls.

All subjects with peripheral occlusive arteriosclerosis had pathological findings documented by plethysmography, oscillography, and angiography. These tests were not carried out in either demented patients or in control subjects. Palpation of the peripheral arteries in these subjects gave, however, normal findings.

LIPIDS Comparison of the blood lipid findings in arteriosclerotic demented patients and controls showed that cholesterol, triglycerides, and lipoprotein fractions separated by nephelometry, were not significantly different (Table 2). Patients with arteriosclerotic dementia showed a higher percentage of phosphatidylinositol (Pl) and lysolecythins (Lys), as well as sphingomyelins (Sph) (see Table 4).

GLUCOSE AND URIC ACID These were not significantly different in the three groups (Table 2, and Table 5). Diabetes (fasting blood sugar above $120 \mathrm{mg}$ per $100 \mathrm{ml}$ with pathological glucose tolerance test) was recorded in two patients with arteriosclerotic dementia and four with peripheral occlusive arteriosclerosis, and one control. Elevated plasma uric acid levels (>7 mg\%) were found in three patients with arteriosclerotic dementia and four with peripheral occlusive arteriosclerosis, but in none of the controls. None of the patients had clinical gout.

haEmocoagulation Platelet number, PT, PTT, and ELT did not differ significantly between patients with arteriosclerotic dementia and controls. Fibrinogen levels were, however, significantly elevated in the arteriosclerotic dementia group (Table 3).

COMPARISON BETWEEN PATIENTS WITH ARTERIOSCLEROTIC DEMENTIA AND PERIPHERAL OCCLUSIVE ARTERIOSCLEROSIS It was soon evident that patients with peripheral occlusive arteriosclerosis had a significantly higher incidence of hypertriglyceridaemia than patients with arteriosclerotic dementia (Table 5). Therefore, by using the N.I.H. protocol (Fredrickson, 1968) for the typing of hyperlipoproteinaemia, we could de- 0 tect a significantly higher incidence of Fredrick-

TABLE 6

DISTRIBUTION OF FREDRICKSON HYPERLIPOPROTEINAEMIA PHENOTYPES AMONG PATIENTS WITH CEREBRAL ARTERIO- $\frac{\bar{\sigma}}{\bar{\sigma}}$ SCLEROSIS AND PERIPHERAL OCCLUSIVE ARTERIOSCLEROSIS $\frac{\bar{\omega}}{\bar{\sigma}}$

\begin{tabular}{cccc}
\hline $\begin{array}{c}\text { Fredrickson } \\
\text { types }\end{array}$ & $\begin{array}{c}\text { Arteriosclerotic } \\
\text { dementia }\end{array}$ & Controls & $\begin{array}{c}\text { Peripheral } \\
\text { occlusive } \\
\text { arteriosclerosis }\end{array}$ \\
\hline
\end{tabular}

\begin{tabular}{|c|c|c|c|}
\hline I & -- & - & - \\
\hline IIa & 1 & 3 & 1 \\
\hline $1 \mathrm{IIb}$ & 1 & $i$ & 6 \\
\hline III & $\overline{2}$ & $\overline{3}$ & $\overline{8}$ \\
\hline $\begin{array}{l}\text { Iv } \\
\text { to }\end{array}$ & - & - & - \\
\hline
\end{tabular}

son's phenotypes among the peripheral arteri $\frac{\stackrel{9}{0}-\frac{}{2}}{2}$ sclerotic group than among controls or arterio sclerotic dementia patients (Table 6). We did not $\frac{0}{\mathbb{D}}$ detect any floating beta-lipoproteins, althoug sinking pre-beta lipoproteins (Rider et al., 197G) were detected in two patients in each group.

\section{DISCUSSION}

Our data show that plasma lipid and lipoprotein levels do not differ significantly between con-a trols and patients with arteriosclerotic dementia. के Only two phospholipid subclasses, sphingomyelin and phosphatidylinositol + lysolecythins $\frac{3}{3}$ were in a higher percentage in the latter group. Coagulative parameters were not markedlyo altered in either group, and only fibrinogen was significantly more elevated in patients with arteriosclerotic dementia. A comparison be- 0 tween demented and peripheral occlusive arteriosclerotic patients showed a significantly higherố incidence of hypertension in the latter group, and we were also able to detect marked differences음 in plasma lipids and lipoproteins. In particular, peripheral occlusive arteriosclerotic patients had을 more elevated plasma triglycerides with a very high incidence of Fredrickson type IV hyper- $N$ lipoproteinaemia while almost all the arterio-N sclerotic dementia patients had a normal lipid- 
lipoprotein pattern. Diabetes was more frequent in patients with peripheral occlusive arteriosclerosis but, on the whole, plasma glucose levels were not significantly different. Laboratory tests commonly used in the clinical diagnosis of atherosclerosis seem, therefore, to be of little value in evaluating arteriosclerotic dementia, the only exception being fibrinogen levels. Although coagulative parameters were not determined in our peripheral arteriosclerotic patients, it may be pointed out that fibrinogen was shown by Cotton et al. (1972) to be higher in such patients.

On the other hand, patients with peripheral occlusive arteriosclerosis had significantly higher triglyceride levels than control or arteriosclerotic demented patients. This finding, which confirms data by Greenhalgh et al. (1971), was not among the conclusions of the study by Cotton $e t$ al. (1972). This difference was probably due to the use of nephelometry as the only technique for estimating triglyceride-rich particles, while we determined cholesterol and triglycerides as did Greenhalgh et al. (1971), as well as the Fredrickson typing, thus probably providing more complete results.

Arteriosclerotic dementia is the consequence of severe, usually long-standing, anatomical damage to the cerebral arteries. Our study of the biochemical and haemocoagulative parameters in a group of patients with arteriosclerotic dementia failed to detect any significant alteration, with the possible exception of elevated fibrinogen levels. On the other hand, a group of peripheral occlusive arteriosclerotic patients of similar age showed evidence of markedly raised plasma triglyceride levels, a finding already shown by others; it may also be noted that signs of hypercoagulability have been reported in these latter patients. The authors feel that laboratory tests commonly used in the diagnosis of vascular diseases are not adequate in indicating any pathogenic mechanism in arteriosclerotic dementia. In spite of very severe vascular lesions, leading to dementia and focal deficits, laboratory tests did not indicate any abnormality. Studies in other directions, such as immunology, protein metabolism, and central mediators, are warranted.

The assistance of Dr E. Agradi is gratefully azknow- ledged, as is that of Messrs G. C. Tonon and L. Fassina.

\section{REFERENCES}

Acheson, J., and Hutchinson, E. C. (1972). Controlled trial of clofibrate in cerebral vascular disease. Atherosclerosis, 15, 177-183.

Bittner, D. L., and Manning, J. (1966). Automated neocuproine glucose method: critical factors and normal values. In Automation in Analytical Chemistry, pp. 33-36. Edited by L. T. Skeggs. Mediad: New York.

Block, W. D., Jarrett, K., Jr, and Levine, J. B. (1965). Use of a single color reagent to improve the automated determination of serum total cholesterol. In Automation in Analytical Chemistry, pp. 345-347. Edited by L. T. Skeggs. Mediad: New York.

Brancale, G. (1970). Osservazioni tromboangiografiche in soggetti arteriopatici con sclerosi vasale. Giornale dell'Arteriosclerosi, 6, 483-490.

Buckell, M. (1958). The effect of citrate on euglobulin methods of estimating fibrinolytic activity. Journal of Clinical Pathology, 11, 403-405.

Cotton, R. C., Bloor, K., and Archibald, G. (1972). Interrelationships between platelet response to adenosine diphosphate, blood coagulation and serum lipids in patients with peripheral occlusive atherosclerosis. Atherosclerosis, 16, 337-348.

Drobrinsky, A. D., and Palamarchuck, G. S. (1969). Quadro clinico e diagnosi dell'arteriosclerosi cerebrale precoce. Minerva Medica, 60, 2282-2287.

Fearnley, C. R., and Chakrabarti, R. (1966). Fibrinolytic treatment of rheumatoid arthritis with phenformin plus ethyloestrenol. Lancet, 2, 757-760.

Fredrickson, D. S., Levy, R. I., and Lindgren, F. T. (1968). A comparison of heritable abnormal lipoprotein patterns as defined by two different techniques. Journal of Clinical Investigation, 47, 2446-2457.

Greenhalgh, R. M., Lewis, B., Rosengarten, D. S., Calnan, J. S., Mervart, I., and Martin, P. (1971). Serum lipids and lipoproteins in peripheral vascular disease. Lancet, 2, 947950.

Heyman, A., Nefzger, M. D., and Estes, E. H., Jr (1961). Serum cholesterol levels in cerebral infarction. Archives of Neurology, 5, 264-268.

Kessler, G., and Lederer, H. (1965). Fluorometric measurement of triglycerides. In Automation in Analytical Chemistry, pp. 341-344. Edited by L. T. Skeggs. Mediad: New York.

Langdell, R. D., Wagner, R. H., and Brinkhous, K. M. (1953). Effect of antihemophilic factor on one-stage clotting tests. Journal of Laboratory and Clinical Medicine, 41, 637647.

Mayer, J. S., Waltz, A. G., Hess, J. W., and Zak, B. (1959). Serum lipids and cholesterol levels in cerebrovascular disease. Archives of Neurology (Chic.), 303-311.

Musser, A. W., and Ortigoza, C. (1966). Automated determination of uric acid by the hydroxylamine method. Technical Bulletin of the Registry of Medical Technologists, 36, 21-25.

Noble, R. P. (1968). Electrophoretic separation of plasma lipoproteins in agarose gel. Journal of Lipid Research, 9, 693-700.

Pendefunda, Gh., Ciobanu, M., Menteanu, E., and Stefanache, F. (1966). Les modifications des triglicérides dans les accidents cérébraux de l'athérosclérose. Revista Medico-Chirurgicala, 70, 877-882. 
Resch, J. A., Okabe, N., Loewenson, R. B., Kimoto, K., Katsuki, S., and Baker, A. B. (1969). Pattern of vessel involvement in cerebral atherosclerosis. Journal of Atherosclerosis Research, 9, 239-250.

Rider, A. K., Levy, R. I., and Fredrickson, D. S. (1970). Sinking pre-beta lipoprotein and the Lp antigen. Circulation, 41 and 42, Abstract III-10.

Rouser, G., Siakotos, A. N., and Fleischer, R. S. (1966).
Quantitative analysis of phospholipids by thin-layer chromatography and phosphorus analysis of spots. Lipids, 1, 85-86.

Stone, M. C., Thorp, J. M., Mills, G. L., and Dick, T. B. S. (1970). Comparison of membrane filtration and nephelo- of metry with analytical ultracentrifugation, for the quantitative analysis of low density lipoprotein fractions. Clinica Chimica Acta, 30, 809-828. 